\title{
Research on Collaborative Interactive Management of Major Infrastructure projects Technology Integration
}

\author{
$\mathrm{Na}$ Zhao ${ }^{1,2, \mathrm{a}^{*}}$ and Shan Liu ${ }^{3, \mathrm{~b}}$ \\ ${ }^{1}$ School of Finance, Harbin University of Commerce, Harbin, China \\ ${ }^{2}$ School of Economic and Management, Harbin Institute of Technology, Harbin, China \\ ${ }^{3}$ Audit Office of Xizang Autonomous Region, Lasa, China \\ azhaona@hit.edu.cn \\ b11877700@qq.com
}

Keywords: Major infrastructure projects (MIP); Collaborative Management; Technology Integration

\begin{abstract}
Major infrastructure projects (MIP) are of great importance to the global economic and social development. Major infrastructure projects such as large bridges, urban high-speed railways and highways are characterized by large scale, advanced technology and complex processes. This requires the efficient use of major engineering techniques, so that MIP can be successfully implemented. In addition, there is a need to reduce environmental pollution and save resources and energy to achieve sustainable high-performance construction goals. This paper mainly conducts related research on the integration and synergy relationship of MIP technology. In order to obtain a good MIP technology effect, it is necessary for each participating stakeholder to strengthen their own synergy relationship.
\end{abstract}

\section{Introduction}

Major engineering technologies need to be highly integrated and involve a large number of stakeholders. MIP technology integration synergy relationship formation mechanism refers to the way of integrating collaborative operations around MIP technology activities ${ }^{[1]}$. Therefore, in the process of integrating MIP technology, it is necessary to meet the condition of coordination. By integrating the model of collaborative interaction, it can effectively address the requirements of MIP technology integration and participation in many stakeholders, and promote the further development of major engineering technologies. Therefore, the integration of synergistic major engineering integration model can promote the development of this major project in the direction of high efficiency, energy saving and environmental protection. This has very important practical significance for the further development of the global major engineering construction industry ${ }^{[2]}$.

\section{MIP technology integration features}

The integration of MIP technology needs to be completed in cooperation with various stakeholders through major projects, and the integration of various stakeholders will constitute MIP technology. Major project construction activities involve multiple production links such as design, construction and maintenance. It has the characteristics of large investment scale, long construction period, many parties involved in interest, and a wide range of specialties. These characteristics have led to a surge in the number of MIP technical tasks and participating organizations, and the components are complex and variable ${ }^{[3]}$. The integration of MIP technology and its relationships constitute a complex system. The system consists of multiple components or elements, each of which produces characteristics of a particular functional system through interactions and interdependent relationships ${ }^{[4]}$.

Factor complexity. The construction of major projects involves a number of tasks and sub-tasks, and there is an interdependence between tasks. The high dependence of major engineering tasks ${ }^{[5]}$. This leads to the collaboration and cooperation of each link in the process of technology integration. The high degree of dependence of the integration task will inevitably lead to the complexity of the relationship between the participating stakeholders, as shown in Fig 1. 


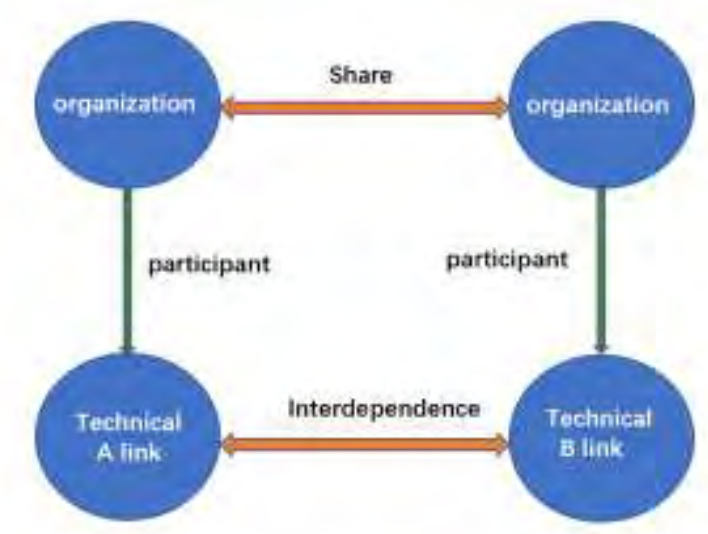

Figure 1. The relationship between the participating stakeholders

MIP technology integrates system elements with complex interactions such as resource exchange, knowledge sharing, technology transfer and information transfer ${ }^{[6]}$. This affects the quality and speed of the flow, which affects the integration behavior of the system. The more complex the system components are, the more frequently information, energy, and material exchanges occur. Thus, the knowledge flow, resource flow, and information flow formed by the mutual relationship between elements are more complicated.

Functional specificity. The requirements of MIP technology are taken as the overall input of major engineering systems, and the mechanical equipment and materials, technology, capital, information and human resources required for technical integration activities are specific inputs. After a series of information transfer, task execution, resource integration, process processing, and finally, it outputs integrated products that meet the requirements. This process embodies the MIP technology integration system as a whole, and finally achieves the overall goal of MIP technology through a series of functions ${ }^{[7]}$.

\section{The integration of complex interests}

The major engineering team is a non-independent economy with the goal of completing major projects and the formation of a coalition of independent participants with different tasks. Since the participating parties are independent organizations, they have their own interests and expected benefits in the MIP construction process. They are just a consortium formed for the temporary construction of the MIP. It has the characteristics of one-time, temporary and many stakeholders. This has led to more frequent, dynamic and complex cross-organizational cooperation activities for building MIPs. Its characteristics mainly occur in the three stages of MIP pre-determination, design and construction. The integration interests of different stages of MIP are different, and the importance of different stakeholders in different stages is different, as shown in Fig 2.

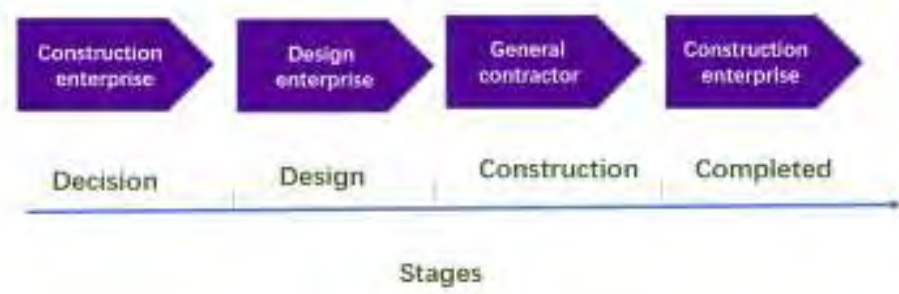

Figure 2. The integration interests of different stages of MIP are different

It describes the dynamic evolution of the role of technology integration stakeholders at different stages of a major project. In the design and construction phases of the MIP, the design unit and the construction unit act as the core stakeholders of the integration ${ }^{[8]}$. Then, the chief architect or engineer and the general contractor work together as system integrators. This has resulted in two major system integrators for major projects, dispersed throughout the design and construction phases. In the major engineering design phase, the design unit formulates an integrated design plan to achieve the technical goals, and clarifies the technical integration content and technical indicators. At this stage, the design organization organizes relevant technical research to ensure that the design plan is consistent with the technical integration goal. At the same time, the technology integration content is adjusted according to the changes in MIP requirements. This approach combines resources and reduces conflicts between stakeholders. In the construction phase, the 
general contractor integrates the technologies of all parties and integrates the work related to technology integration into the general contracting scope. There are levels and transitions between the integrated stakeholders. The design unit and the construction unit work independently and cooperate with each other. On the whole, they are relatively independent from each other, but they are closely related in the specific engineering stage ${ }^{[9]}$.

The MIP technology integration system is coordinated and interacted by Systems Integrators, subcontractors, suppliers, research institutions, governments, and users. Different stakeholders play different roles and have obvious boundaries. The connection medium of the stakeholders is also different. Any change in one stakeholder or subsystem will affect the entire system. The MIP technology integration system is a combination of multiple interconnected subsystems. Subsystems are diverse and interrelated in complexity. Its overall performance cannot be equated with a simple sum of individual subsystems.

\section{Ways to integrate collaborative interaction with MIP technology}

Interested parties actively participating. The technical integration of major projects also has great differences at various stages. This also requires creating a MIP organizational environment with a good integration atmosphere and building a long-term strategic partnership with MIP stakeholders. This will promote more participation of stakeholders in the technical integration of this major project. Because the technical integration of major projects has a large number of participating stakeholders, it also requires the existence of an integrated leading organization, and on this basis to build a suitable relationship model. Then, based on the effective integration of all parties' resources, it realizes the synergy between organizational integration and technology integration.

Reasonable choice of partners. In order to achieve integrated and collaborative cooperation, it is necessary to make reasonable choices for partners. Moreover, it needs to fully consider the market competitiveness of partners, the experience of cooperation and integration, and the willingness of leadership to integrate. This kind of non-contractual relationship can guarantee the stability and continuity of cooperation between the major projects involved in the stakeholders ${ }^{[10]}$. After building a system relationship with a partner, it also requires proper relationship management. Through scientific and rational organization and management, it can effectively reduce the risks and conflicts that may exist in the integration process, and further strengthen the resource sharing and information communication capabilities among the various participants. It can be said that through a reasonable organizational relationship management model, it can more effectively integrate various knowledge resources and ensure the stability of resource flows between organizations.

Integrating Internet resources. In recent years, the global Internet technology has been developed to a certain extent, and it has been widely used in major projects. The main components of MIP technology include construction units, general contractors, design consulting units, and research institutions. It is dependent on major projects, but is independent of a construction activity of MIP. In the process of integration and construction, it needs to take the needs of major projects as their own guidance. Moreover, it aims to achieve a good MIP technology effect by integrating technology. With the help of Internet technology governance and maintenance, it can also promote open communication and collaboration across organizations. It is also an effective way to achieve collaborative integration of MIP technology.

\section{Synergistic research on MIP technology integration}

Evolutionary path of collaborative integration. If the various stakeholders cannot complete the corresponding integration work separately, it is necessary to carry out the technical integration of major projects through the mode of mutual cooperation. In order to achieve a synergistic effect of good technology integration, it is necessary to carry out research work on integrating synergies from multiple aspects. Moreover, it needs to sort out the cluster collaborative integration, and then summarize the evolutionary path of collaborative integration, as shown below. 


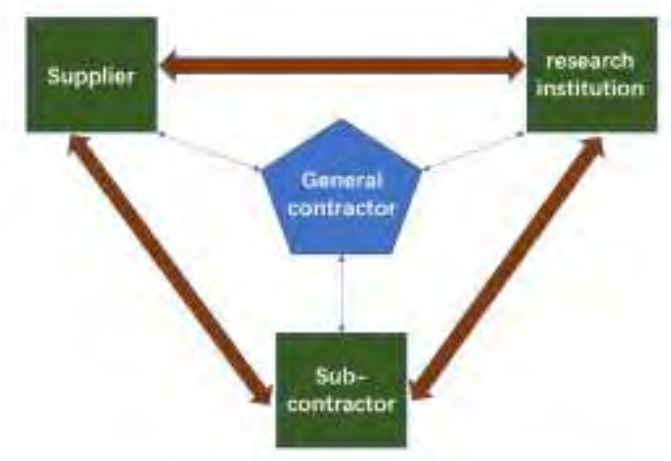

Figure 3 Analysis of the evolutionary approach of collaborative integration

Integrating the synergy dimension of stakeholders. With the continuous development of open integration, the technical integration of major projects needs to be completed by different disciplines, different levels and different types of organizations. This also requires a focused study of the multidimensional interests of the various stakeholders involved. In the integration system, the synergy mechanism between the various stakeholders involved needs to have a positive impact on the integration. Moreover, it needs to take the difference between various stakeholders and the dynamic balance of synergy as the core part.

It can be divided into two aspects, horizontal and vertical. Among them, horizontal collaborative integration refers to the coordination among various stakeholders among organizations, and needs to study the operational mechanism and performance model. Vertical collaborative integration refers to the synergy between various stakeholders in the supply chain. It mainly needs to study and analyze the collaborative integration model, integration ability and various influencing factors of various participating stakeholders.

\section{Conclusion}

In order to ensure the smooth implementation of the project, all stakeholders of major projects must continuously integrate and optimize related technologies, and thereby improve economic and social benefits. In order to obtain a good MIP technology effect, it is necessary for each participating stakeholder to strengthen their own synergy relationship. In addition, this requires technology integration to enable the full play of the role of the various parties, and to enhance the technical integration of the entire major project, thereby escorting the healthy and orderly development of major infrastructure projects.

\section{Acknowledgments}

This work was supported by the National Natural Science Foundation of China (Grant nos. 71390522 and 71601058), the Natural Science Foundation of Heilongiiang of China (Grant number QC2017084), and Heilongjiang Postdoctoral Foundation of China.

\section{References}

[1] Zhao N, An S. "Collaborative management of complex major construction projects: Any logic-based simulation modelling". Discrete Dynamics in Nature and Society, vol. 10, pp. 1-8, 2016.

[2] Zeng SX, Ma HY, Lin H, Zeng RC, Tam VWY. "Social responsibility of major infrastructure projects in China". International Journal of Project Management, vol. 33, no. 3, pp. 37-548, 2015.

[3] Varga L, Grubic T, Greening P, Varga S, Camci F, Dolan T. "Characterizing conversion points and complex infrastructure systems: Creating a system representation for agent - based modelling". Complexity, vol. 19, no. 6, pp. 30-43, 2014.

[4] Thornton H. "An Enquiry into the Nature and Effects of the Paper Credit of Great Britain". Routledge, 2017.

[5] Katalin G, Meggyes T, Fenyvesi E. “Engineering Tools for Environmental Risk Management", CRC Press, 2015

[6] Stern MJ, Coleman KJ. "The multidimensionality of trust: Applications in collaborative natural resource management”. Society \& Natural Resources, vol. 28, no.2, pp. 117-132, 2015

[7] Yang D, He Q, Cui Q, et al. Organizational Citizenship Behavior in Construction Megaprojects[J]. Journal of Management in Engineering, 2018, 34(4). 
[8] Pauget B and Wald A. "Relational competence in complex temporary organisations: The case of a French hospital construction project network". International Journal of Project Management, vol. 31, no. 2, pp. 200-211, 2013.

[9] Zeng W, Zhang J, Wang H, et al. Supplier development and its incentives in infrastructure mega-projects: A case study on Hong Kong-Zhuhai-Macao Bridge project[J]. Frontiers of Engineering Management, 2018, 5(1):88-97.

[10] Du J, El-Gafy M. "Virtual organizational imitation for construction enterprises: Agent-based simulation framework for exploring human and organizational implications in construction management". Journal of Computing in Civil Engineering, vol. 26, no. 3, pp. 282-297, 2012. 